\title{
Female genital cutting: prevalence, knowledge, and attitudes of Sohag University level students, Upper Egypt.
}

\author{
Fouad M. A. Yousef*, Ahmed Fathy Hamed* and Nour El-Hoda Mostafa ** \\ *Public Health and Community Medicine department, Sohag Faculty of Medicine, \\ ** Obstetric and Gynecological, Faculty of Nursing, Sohag University.
}

Received: January 2016 Accepted: March 2016

\begin{abstract}
Background: Egypt showed high prevalence of female genital cutting (FGC). FGC had many harmful physical, psychological and sexual effects. Many efforts had been established to raise awareness about FGC and to decrease its incidence. Education may play a role to change the attitude towards FGC. Objective: This study is conducted in Sohag University to estimate the prevalence of FGC and to measure student's (including males) knowledge and attitudes toward FGC and to identify the reasons behind supporting or rejecting FGC practice.

Participants and methods: This is a cross-sectional study that included 1075 students from five faculties (Agriculture, Arts, Commence, Nursing and Education) and technical health institute selected by using simple random sample. A questionnaire was used to collect the relevant data. Statistical analysis was performed using STATA program. Results: The prevalence of FGC was $86.87 \%$. Possible complications of FGC were known by $51-69 \%$ of the students. Thirty-six percent $(36 \%)$ of students supported the FGC practice while $64 \%$ reject it. Males are significantly supporting FGC practice more than females $(42 \%$ vs. $29 \%, \mathrm{p}<0.0001)$. The reasons to support the practice were religious tradition $(18.60 \%)$, cleanliness $(11.63 \%)$, cultural and social tradition $(21.19 \%)$, chastity $(28.68 \%)$ and evidence of femininity $(19.90 \%)$. The reasons to reject practice were no religious support $(29.07 \%)$, painful procedure $(23.15 \%)$, unhealthy procedure (24.56\%) and bad social habit (22.38). Conclusion: One-third of university students were still supporting FGC practice especially males. Effort towards health education, better to include topic about FGC in the curriculum, will help in discontinuation of FGC in the future.
\end{abstract}

Key word: female genital mutilation, knowledge, attitudes, university student, and Egypt.

*Corresponding author, E mail: fouad3s@ @yahoo.com ,_Tel: +201277601847

\section{Introduction}

Female genital cutting (FGC) or female circumcision was defined as partial or total cutting away of the female external genitalia without medical reasons (1). Worldwide, more than 135 million women have been circumcised. Each year, three million girls are estimated to be circumcised by World Health Organization ${ }^{(1,2)}$ mainly from Africa and Middle East with highest prevalence in northeastern Africa (ranges from $80 \%$ to 97\%) (1). The incidence of FGC during the last 2 decades declined in many African countries ${ }^{(1,3,4)}$. However, FGC 
in Egypt did not show any significant decline 1995-2005, despite efforts made to reduce the frequency ${ }^{(5-7)}$. The incidence of FGM is still very high in Upper Egypt in spite of the criminalization law ${ }^{(8)}$. The prevalence of FGC is ranging from $61 \%$ in Lower Egypt to $97 \%$ in Upper Egypt $(5,9,10)$. FGC had many harmful physical, psychological and sexual effects of females ${ }^{(11,12)}$. Many efforts have been established to raise awareness about FGC and to decrease its incidence ${ }^{(13)}$. Education may play a role to change the attitude towards FGC ${ }^{(14,15)}$. This study was conducted to identify the prevalence of FGC among university level female students, to examine the knowledge about FGC of all students including males, to identify their attitudes towards FGC practice and to examine the reasons for supporting or rejecting it.

\section{Participants and Methods:}

\section{Study design:}

This is cross-sectional study

\section{Study setting:}

This study was conducted in Sohag. Sohag is one of the nine governorates of Upper Egypt (Egypt consists of 27 governorates). Sohag have 12 municipalities. The total area of Sohag is $11218 \mathrm{~km}^{2}$ with total population of 4,469,151 according to Central Agency for Public Mobilization and Statistics, Egypt (2014). The total numbers of students were approximately 17,000 students in 2014-2015.

\section{Sample size and randomization:}

Using Sample Size Determination table for survey study developed by Bartlett, Kotrlik, \& Higgins (16) and assuming alpha levels of 0.05 , the necessary sample size was calculated as 370 . Other way to calculate the sample size is by using sample size calculator program. Based on a confidence level of 95 percent, confidence interval $4 \%$ and 16,000 population size, the necessary sample size was calculated as 579. For better result we included 1075 students. The sample size was taken from students in university students from five faculties (Agriculture, Arts, Commence, Nursery and Education) and from technical health institute using simple random sample.

\section{Instruments:}

A questionnaire was established specially for this study after examining some of previous studies about FGC. The questionnaire was tested by asking 60 students to complete the questionnaire. Revision was made and some changes were done. The study was explained to the students. Some teaching rooms were selected randomly and paper questionnaires were distributed to students who were willing to participate in the study. The questionnaires were completed by the students themselves anonymously. The questionnaire divided to two parts. First part questions aimed to measure knowledge of students about FGC while the second part aimed to identify their attitude and their reasons to support or reject this practice.

Administrative and ethical issues including confidentiality and verbal consent were obtained.

\section{Statistical Analysis:}

Statistical analyses were performed using intercooled STATA program version 12.1. Data are presented as counts, percentages, and means. Chi square test was used compare different groups. Level of significance was set at $\mathrm{P}$ value $<0.05$.

\section{Results}

\section{Demographic characteristic:}

This study included 1075 students at $\mathrm{s}$ in Sohag University. Their mean age was $19.66 \pm 1.51$ years. About 55.35\% were 
males and $44.65 \%$ were females. The demographic characteristics of the respondents were shown in table (1).

\section{Prevalence of FGC:}

Among 480 female students 417 were circumcised giving a prevalence of $86.87 \%$. The mean age of circumcision was $7.13 \pm 3.5$. The median age was 7 years (range 1-14)

\section{Knowledge about FGC:}

Table (2) shows the knowledge and beliefs about FGC. Of the possible complications of FGC, $59.63 \%$ of student identified hemorrhage $(57.65 \%$ for males and $62.08 \%$ for females). There is no significant relationship between both sexes as regard identifying hemorrhage as possible complication $(p=0.26)$. Other complications were better identified by females than males. These complications were genital tears and infections $(57.95 \%$ for all students, $49.41 \%$ for males, $68.54 \%$ for females, $\mathrm{p}<0.0001)$, infertility $(50.51 \%$ for all students, $38.99 \%$ for males, $64.79 \%$ for females, $\mathrm{p}<0.0001)$, difficult labor $(69.40 \%$ for all students, $64.87 \%$ for males, $75.00 \%$ for females $\mathrm{p}=0.002$ ), serious complications up to death (58.23\% for all students, $53.45 \%$ for males, $64.17 \%$ for females $\mathrm{p}=<0.0001$ ), and dyspareunia and loss of libido (60.93\% for all students, $56.81 \%$ for males, $66.04 \%$ for females $\mathrm{p}<0.0001$ ). Decrease sexual pleasure in females was identified by $64.19 \%$ of students $(63.70 \%$ of males and $64.79 \%$ of females) while $19.53 \%$ did not know that FGC decreased sexual pleasure in females $(17.31 \%$ of males and $22.29 \%$ of females, $\mathrm{p}=0.009$ ).

Source of Knowledge about FGC:

The main source of information about FGC was TV (and other mass media or internet) $(42.42 \%)$. Other sources were health education sessions, study, friends and family $(16.65 \%, 16.56 \%, 13.11 \%$ and $11.26 \%$ respectively).

\section{Attitude towards FGC:}

Approximately one-third of the students (36.00\%) supported the FGC practice while $64.00 \%$ reject it. Male students more supporting for the practice than females did $(41.85 \%$ of males vs. $29 \%$ of females, $\mathrm{p}<0.0001)$. Reason to support or reject FGC were shown in table (3). The reasons to support the practice of FGC were an important religious tradition $(18.60 \%)$, cleanliness for girls $(11.63 \%)$, cultural and social tradition (21.19\%), chastity $(28.68 \%)$ and evidence of femininity (19.90\%). There is a significant difference between male and females as regard why they supported the practice $(\mathrm{p}=0.01)$. The main difference was that $23.69 \%$ of males thought that FGC was an important religious tradition compared to $9.42 \%$ of females. The reasons to reject practice were painful procedure (23.15\%), unhealthy procedure (24.56\%), no religious support (29.07\%), and bad social habit (22.38). There is a significant difference between males and females as regard why they reject the practice $(p=0.01)$. The main difference was that $19.94 \%$ of males thought FGC as unhealthy procedure compared to $(29.24 \%)$ in females.

\section{Discussion}

In spite of presence of many studies that measure the knowledge and attitude towards FGC, our study is an important one because it includes males and identify their knowledge and altitudes as they are also important decision maker in this issue. Also it includes university student who represent person with high level of education and they are the future 
parents who are responsible for decision of doing this practice.

Despite the effort of WHO to minimize the FGC, the prevalence is still high especially in North Africa ${ }^{(1,2)}$. Previous studies ${ }^{(5,9)}$ showed high prevalence of FGC in Egypt ranging from $61 \%$ in Lower Egypt to $97 \%$ in Upper Egypt. FGC in Egypt did not show any significant decline 1995-2005, despite efforts made to reduce the frequency ${ }^{(5-7)}$. The current study confirmed these finding. It showed a high prevalence of FGC (87\%) among female university level students. This is near to results reported in Sohag $(89 \%){ }^{(8)}$, and in Upper Egypt $(85 \%){ }^{(10)}$. The mean age of circumcision in current study was $7.13 \pm$ 3.5. This was near to that reported by other studies (11, 17, 18). Egyptian demography and health survey reported that more than half of FGC were done between seven and ten years of age at the time of circumcision, and virtually all of the women were circumcised before age 15 years ${ }^{(15)}$. This reflects the fact that, in Egypt, traditionally girls are circumcised slightly before or at puberty (9).

This study showed fair knowledge about FGC. About 51-69\% of the students knew possible complications of FGC such as hemorrhage $(60 \%)$, genital tears $\&$ infections (58\%), infertility (51\%), difficult labor (69\%), serious complications up to death (58\%), dyspareunia and loss of libido (61\%), and decrease sexual pleasure (64\%). Females had significant good knowledge than males. This may because females more concerned with the issue of FGC. The main source of information about FGC was TV (and other mass media or internet) (42\%). T.V and mass media were reported as main sources of information for reproductive health in many studies ${ }^{(19-23)}$. The availability of internet for university to students made it playing an important role as source of information. This finding is reported by study in Egypt ${ }^{(22)}$ and India ${ }^{(24)}$. Health education sessions and study come after TV and internet as a source of information reported by students $(17 \%$ each). These findings indicate that health education and study played a role in improving the knowledge of students about FGC.

Previous studies $(14,15,25-28)$ aimed to examine Egyptian women's attitudes and beliefs about female genital cutting found that $54-86 \%$ of women support this practice. Our study showed that only $36 \%$ supported the FGC practice. This result is lower than that reported from previous studies because of high level of education of participants. Dalal et al ${ }^{(14)}$, found that women with higher level education were three times more likely to discontinue the practice than those with no education. EDHS, $2008{ }^{(15)}$ reported that $43 \%$ of secondary or higher women feel that the practice of circumcision should continue.

EDHS, $2008{ }^{(15)}$ reported that there is no difference between males and females as regard supporting the practice. The current study showed that, male students more supporting for the practice than females (42\% vs. 29\%). AsekunOlarinmoye \& Amusan ${ }^{(29)}$ found that a greater proportion of men than women did not want the practice of FGM stopped in the pre-intervention stage. After health education intervention, there was a statistically significant decrease in the proportion of males who did not want the practice of FGM stopped. Tag-Eldin et al (18) found that father played minor role as roles as decision-makers for the practice $(9 \%)$ compared to mothers $(65 \%)$ and to the 
family as a whole (24\%). However, especial effort should also be given towards health education of males concerning FGC and its complication.

This study showed that, the reasons to support the practice of FGC were that FGC is an important religious tradition (19\%), cleanliness for girls (12\%), cultural and social tradition (21\%), chastity $(29 \%)$ and evidence of femininity (20\%). Tag-Eldin et al (18) found that, the reasons for supporting FGC practice were religious tradition $(33 \%)$, cleanliness for girls (19\%), cultural and social tradition (18\%) and chastity (16\%). Previous studies (28, 30, 31) showed that the most important cause for supporting FGC is religious requirement. The current study showed only $19 \%$ of students saw that FGC is a religious requirement. This finding indicated that better education changed the beliefs related FGC especially for younger women. EDHS, $2008^{(15)}$ supported this finding by reporting that, women under age 25 were less likely than older women to see circumcision as a religious requirement. Our finding showed that $23 \%$ of males thought that FGC was an important religious tradition compared to $9 \%$ of females. This finding also emphasizes the importance of giving more effort towards health education of males concerning FGC.

The reasons to reject practice, in this study, were painful procedure (23\%), unhealthy procedure $(25 \%)$, no religious support (29\%), and bad social habit $(22 \%)$. The main cause to reject the practice was no religious support (32\%) in males while it was unhealthy procedure $(29 \%)$ in females. The reasons for rejecting the procedures reported by Tag-Eldin et al (18) were unhealthy and painful procedure (54\%), unnecessary for females (18\%), no religious support
(20\%) and bad social habit (4\%). These differences can be attributed to differences in the composition of the groups. Our study was composed of university students including males and females, while the Tag-Eldin et al (18) study composed from female school students.

\section{Conclusion}

In conclusion, this study showed improved knowledge and attitudes of university level students towards FGC. However, about one-third of student still supporting this practice especially males. Effort towards health education for both male and female students about FGC, better to include topic about FGC in the curriculum, will help in discontinuation of FGC in the future.

\section{Acknowledgements}

The authors would like to thank the students who participated in the study.

\section{Conflicts of interest}

There are no conflicts of interest.

\section{References}

1) Stanley Y, Abderrahim $\mathrm{N}$ and Zhuzhuni A (2004): Female Genital Cutting in the Demographic and Health Surveys: a Critical and Comparative Analysis. Calverton, Md.: ORC Macro. Measure DHS.

2) World Health Organization (2008): Eliminating female genital mutilation: an interagency statement UNAIDS, UNDP, UNECA, UNESCO, UNFPA, UNHCHR, UNHCR, UNICEF, UNIFEM, WHO. Geneva, Switzerland.

3) Snow RC, Slanger TE, Okonofua FE, Oronsaye F and Wacker J (2002): Female genital cutting in southern urban and peri-urban Nigeria: self-reported validity, social determinants and secular decline. Trop Med Int Health;7(1):91100 . 
4) Msuya SE, Mbizvo E, Hussain A, Sundby J, Sam NE and StrayPedersen B (2002): Female genital cutting in Kilimanjaro, Tanzania: changing attitudes? Trop Med Int Health;7(2):159-65.

5) El-Zanaty $F$ and Way A Egypt Demographic and Health Survey 2000. editor: Calverton, MD: Ministry of Health and Population [Egypt], National, Population Council and ORC Macro; 2001.

6) Afifi M (2007): Female genital mutilation in Egypt. Lancet; 369(9576): 1858.

7) Yoder $\mathbf{P}$, Abderrahim $\mathbf{N}$ and Zhuzhuni A (2004): Female Genital Cutting in the Demographic and Health Surveys: A Critical and Comparative Analysis. Calverton, MD: DHS Comparative Reports No 7, ORC Macro. 8) Rasheed SM, Abd-Ellah $\mathrm{AH}$ and Yousef FM (2011): Female genital mutilation in Upper Egypt in the new millennium. International Journal of Gynecology \& Obstetrics;114(1):47-50.

9) El-Gibaly O, Ibrahim B, Mensch BS and Clark WH (2002): The decline of female circumcision in Egypt: evidence and interpretation. Soc Sci Med;54(2):205-20.

10) Hassanin IM, Saleh $R$, Bedaiwy AA, Peterson RS and Bedaiwy MA (2008): Prevalence of female genital cutting in Upper Egypt: 6 years after enforcement of prohibition law. Reprod Biomed Online;16 Suppl 1:27-31.

11) Anis TH, Aboul Gheit S, Awad HH and Saied HS (2012): Effects of female genital cutting on the sexual function of Egyptian women. A crosssectional study. J Sex Med;9(10):268292.

12) Elnashar $A$ and Abdelhady $R$ (2007): The impact of female genital cutting on health of newly married women. Int $\mathbf{J}$ Gynaecol Obstet;97(3):238-44.

13) von der Osten-Sacken $T$ and Uwer $T$ (2007): Is female genital mutilation an Islamic problem? Middle East Quarterly.

14) Dalal K, Lawoko $S$ and Jansson B (2010): Women's attitudes towards discontinuation of female genital mutilation in Egypt. Journal of injury \& violence research;2(1):41-5.

15) El-Zanaty F and Way A Egypt Demographic and Health Survey 2008. editor. Cairo, Egypt: Ministry of Health,El-Zanaty and Associates, and Macro International.; 2009

16) Bartlett JE, Kotrlik JW and Higgins CC (2001): Organizational research: Determining appropriate sample size in survey research appropriate sample size in survey research. Information technology, learning, and performance journal;19(1):43.

17) Shaeer O and Shaeer E (2013): The Global Online Sexuality Survey: Public Perception of Female Genital Cutting among Internet Users in the Middle East. J Sex Med.

18) Tag-Eldin MA, Gadallah MA, AlTayeb MN, Abdel-Aty M, Mansour E and Sallem $M$ (2008): Prevalence of female genital cutting among Egyptian girls Bull World Health Organ;86(4):269-74.

19) Abdel Megeid A, El Sheikh S, El Gindy $M$ and El Araby M (1996): Knowledge and attitude about reproductive health and HIV/AIDS among family planning clients. . Eastern Mediteranian Health Journal;2(3):45969.

20) El-Tawila $S$, Ibrahim B, Sallam $S$, El-Gibaly $O$ and El-Sahn F (1999 ): Transition to Adulthood: A National 
Survey of Egyptian Adolescents. . Cairo: Population Council.

21) El-Sadek AA, Abdel-Hakiim M, Kasim K and Abd-Elhady AS (2008 ): Knowledge and attitude of adolescent girls towards reproductive health care in cairo, Egypt The Egyptian Journal of Community Medicine 26(1).

22) El Gelany S and Moussa O (2013): Reproductive health awareness among educated young women in Egypt Int $\mathbf{J}$ Gynaecol Obstet;120(1):23-6.

23) Sallam SA, Mahfouz AA and Dabbous NI (2001 ): Reproductive health of married adolescent women in squatter areas in Alexandria, Egypt East Mediterr Health J;7(6):935-42.

24) McManus A and Dhar L (2008): Study of knowledge, perception and attitude of adolescent girls towards STIs/HIV, safer sex and sex education: (a cross sectional survey of urban adolescent school girls in South Delhi, India) BMC Womens Health;8:12.

25) Afifi $M$ and von Bothmer $M$ (2007): Egyptian women's attitudes and beliefs about female genital cutting and its association with childhood maltreatment. Nurs Health Sci;9(4):2706.

26) Afifi M (2009): Women's empowerment and the intention to continue the practice of female genital cutting in Egypt. Arch Iran Med;12(2):154-60.
27) Afifi M (2010): Egyptian evermarried women's attitude toward discontinuation of female genital cutting. Singapore Med J;51(1):15-20.

28) Almroth L, Almroth-Berggren $V$, Hassanein OM, El Hadi N, Al-Said SS, Hasan SS, et al. (2001): A community based study on the change of practice of female genital mutilation in a Sudanese village. Int J Gynaecol Obstet;74(2):17985.

29) Asekun-Olarinmoye EO and Amusan OA (2008): The impact of health education on attitudes towards female genital mutilation (FGM) in a rural Nigerian community. The European journal of contraception \& reproductive health care : the official journal of the European Society of Contraception;13(3):289-97.

30) Klouman E, Manongi $R$ and Klepp KI (2005): Self-reported and observed female genital cutting in rural Tanzania: associated demographic factors, HIV and sexually transmitted infections. Trop Med Int Health;10(1):105-15.

31) Allam MF, de Irala-Estevez J, Fernandez-Crehuet Navajas $R$, Serrano del Castillo A, Hoashi JS, Pankovich MB, et al. (2001): Factors associated with the condoning of female genital mutilation among university students. Public health;115(5):350-5. 
Table 1: Demographic Characteristics of Respondents

\begin{tabular}{|l|c|}
\hline \multicolumn{1}{|c|}{ Characteristics } & Total \\
No. & $(\%)$ \\
\hline Age & $19.66(1.51)$ \\
Mean (SD) & $20(17-23)$ \\
Median (range) & \\
\hline Sex & $595(55.35)$ \\
Male & $480(44.65)$ \\
Female & \\
\hline Type of study & $170(15.81)$ \\
Faculty of Agriculture & $188(17.49)$ \\
Faculty of Arts & $194(18.05)$ \\
Faculty of Nursery & $181(16.84)$ \\
Faculty of Commence & $185(17.21)$ \\
Faculty of Education & $157(14.60)$ \\
Technical Health Institute & \\
\hline Grade & $266(24.74)$ \\
1 & $261(24.28)$ \\
2 & $285(35.81)$ \\
3 & $163(15.16)$ \\
4 & \\
\hline Residence & $599(55.72)$ \\
Rural & $476(44.28)$ \\
Urban & \\
\hline Religion & $883(82.14)$ \\
Muslim & $192(17.86)$ \\
Christian & \\
\hline Religious Commitment & $292(27.16)$ \\
Religious & $688(64.00)$ \\
To some extent & $95(8.84)$ \\
Not Religious & \\
\hline Father education & $190(17.67)$ \\
Not educated & $195(18.14)$ \\
Primary or preparatory & $585(54.42)$ \\
Secondary or technical & $105(9.77)$ \\
University or higher & $396(36.84)$ \\
\hline Mother education & $189(17.58)$ \\
Not educated & $438(40.74)$ \\
Primary or preparatory & $52(4.84)$ \\
Secondary or technical & \\
University or higher & \\
\hline Father work & $(10.31 .49)$ \\
Not work & \\
Work & \\
\hline Mother work & \\
Not work & \\
Work & \\
\hline
\end{tabular}


Table 2: Knowledge about FGM

\begin{tabular}{|c|c|c|c|c|}
\hline & \multicolumn{3}{|c|}{ Response } & \multirow[t]{3}{*}{ P value } \\
\hline & Yes & No & Don't Know & \\
\hline & Number (\%) & Number (\%) & Number $(\%)$ & \\
\hline \multicolumn{5}{|l|}{ The possible complications of FGM are } \\
\hline Hemorrhage & $641(59.63)$ & $220(20.47)$ & $214(19.91)$ & \multirow{3}{*}{0.26} \\
\hline - Male & $343(57.65)$ & $124(20.84)$ & $128(21.51)$ & \\
\hline - Female & $298(62.08)$ & $96(20.00)$ & $86(17.92)$ & \\
\hline Genital tears \& infections & $623(57.95)$ & $220(20.47)$ & $232(21.58)$ & \multirow{3}{*}{$<0.0001$} \\
\hline - Male & $294(49.41)$ & $135(22.69)$ & $166(27.90)$ & \\
\hline - Female & $329(68.54)$ & $85(17.71)$ & $66(13.75)$ & \\
\hline Infertility & $543(50.51)$ & $209(19.44)$ & $323(30.05)$ & \multirow{3}{*}{$<0.0001$} \\
\hline - Male & $232(38.99)$ & $138(23.19)$ & $225(37.82)$ & \\
\hline - Female & $311(64.79)$ & $71(14.79)$ & $98(20.42)$ & \\
\hline Difficult labour & $746(69.40)$ & $185(17.21)$ & $144(13.40)$ & \multirow{3}{*}{0.002} \\
\hline - Male & $386(64.87)$ & $116(19.50)$ & $93(15.63)$ & \\
\hline - Female & $360(75.00)$ & $69(14.37)$ & $51(10.63)$ & \\
\hline Serious complications up to death & $626(58.23)$ & $248(23.07)$ & $201(18.70)$ & \multirow{3}{*}{$<0.0001$} \\
\hline - Male & $318(53.45)$ & $141(23.70)$ & $136(22.86)$ & \\
\hline - Female & $308(64.17)$ & $107(22.29)$ & $65(13.54)$ & \\
\hline Decrease sexual pleasure in females & $690(64.19)$ & $210(19.53)$ & $175(16.28)$ & \multirow{3}{*}{0.009} \\
\hline - Male & $379(63.70)$ & $103(17.31)$ & $113(18.99)$ & \\
\hline - Female & $311(64.79)$ & $107(22.29)$ & $62(12.28)$ & \\
\hline Dyspareunia and loss of libido & $655(60.93)$ & $269(25.02)$ & $151(14.05)$ & \multirow{3}{*}{$<0.0001$} \\
\hline - Male & $338(56.81)$ & $143(24.03)$ & $114(19.16)$ & \\
\hline - Female & $317(66.04)$ & $126(26.25)$ & $37(7.71)$ & \\
\hline
\end{tabular}

Table 3: Reasons for Supporting or Rejecting FGM

\begin{tabular}{|c|c|c|c|c|}
\hline Variable & Male & Female & Total & \\
\hline \multicolumn{5}{|c|}{ Reasons to support practice } \\
\hline - Religious & $59(23.69)$ & $13(9.42)$ & $72(18.60)$ & \multirow{5}{*}{0.01} \\
\hline - Cleanliness & $26(10.44)$ & $19(13.77)$ & $45(11.63)$ & \\
\hline - Cultural/social issues & $49(19.68)$ & $33(23.91)$ & $82(21.19)$ & \\
\hline - Chastity & $71(28.51)$ & $40(28.99)$ & $111(28.68)$ & \\
\hline - Evidence of femininity & $44(17.67)$ & $33(23.91)$ & $77(19.90)$ & \\
\hline \multicolumn{5}{|l|}{ Reasons to reject practice } \\
\hline - Painful procedure & $79(22.83)$ & $86(25.15)$ & $165(23.15)$ & \multirow{4}{*}{0.01} \\
\hline - Unhealthy procedure & $69(19.94)$ & $100(29.24)$ & $169(24.56)$ & \\
\hline - No religious support & $112(32.37)$ & $88(25.73)$ & $200(29.07)$ & \\
\hline - Bad social habit & $86(24.86)$ & $68(19.88)$ & $154(22.38)$ & \\
\hline
\end{tabular}

